\title{
Imunorreatividade da p53 associada à ausência de mutações no gene TP53 em linfomas caninos
}

\author{
Immunostaing of p53 associated with absence of mutations in TP53 gene in dogs with lymphoma
}

\author{
Sabryna Gouveia Calazans ${ }^{\mathrm{I}}$ Sabrina Marin RodigheriII Simone Crestoni Fernandes ${ }^{\text {III }}$ \\ Reneé Laufer Amorim $^{\mathrm{IV}}$ Júlio Lopes Sequeira' ${ }^{\mathrm{IV}}$ Janete Apparecida Desidério SenaV $^{\mathrm{V}}$ \\ Carlos Roberto Daleck ${ }^{\mathrm{VI}}$
}

\begin{abstract}
Sabendo-se da influência das mutações no gene TP53 no desenvolvimento das neoplasias e da discrepância entre os resultados obtidos pelas técnicas de sequenciamento $e$ imunoistoquímica, esta pesquisa teve como objetivo relacionar a sequência do TP53 com a imunorreatividade da p53. Foram obtidas amostras de linfoma de 12 cães. O diagnóstico histopatológico foi determinado pela classificação de Kiel. O imunofenótipo e a imunomarcação da p53 foram determinados por imunoistoquímica. Para reação com a p53, utilizou-se anticorpo policlonal anti-p53 (CM1) na diluição de 1:500. A região do gene TP53 compreendida entre os exons quatro $e$ nove foi amplificada por PCR e submetida ao sequenciamento. Apesar dos resultados obtidos pela imunoistoquímica, nenhuma mutação foi encontrada nas sequências analisadas. Concluise que a imunorreatividade da p53 pela imunoistoquímica não pode ser atribuída à presença de mutações no domínio central do gene TP53.
\end{abstract}

Palavras-chave: cão, imunoistoquímica, linfossarcoma, p53, sequenciamento.

\section{ABSTRACT}

TP53 mutations are usually involved in cancer, but sequencing and immunohistochemistry results are often controversial. Thus, the aim of this study was to associate TP53 sequence with p53 immunostaining in dogs with lymphoma. Tumor samples were collected from 12 dogs with lymphoma and were included in this study. Histopathological diagnosis was performed according to Kiel classification. Immunohistochemistry was performed to identify immunophenotype as well as p53 expression. Polyclonal antibody anti-p53 (CM1) was used at a 1:500 dilution. The region that encompasses exons 4-9 was amplified by $f$ PCR reactions and sequencing was then performed. Nevertheless, gene mutations were not observed in any sequence. In conclusion, immunoreactivity of p53 by means of immunohistochemistry should not be indicator of presence of mutations in the core domain of TP53 gene.

Key words: dog, imunohistochemistry, lymphosarcoma, p53, sequencing.

Mutações no gene supressor de tumor TP53 nem sempre apresentam resultados compatíveis com a imunorreatividade da p53, e essa discrepância tem sido alvo de crescente interesse nas pesquisas relacionadas ao gene (CESARMAN et al., 1993; MARTINEZ-DELGADO et al., 1997; OKA et al., 1998). Sabendo-se da influência das alterações do gene TP53 no desenvolvimento das neoplasias, este trabalho teve

IMédica Veterinária Autônoma. Rua Nélio Guimarães, nº 170, 14025-290, Ribeirão Preto, SP, Brasil. E-mail: sgcalazans@gmail.com. Autor para correspondência.

"Faculdade Integrada de Campo Mourão, Campo Mourão, SP, Brasil.

IIIPrograma de Pós-graduação, Faculdade de Medicina, Universidade de São Paulo,(USP), São Paulo, SP, Brasil.

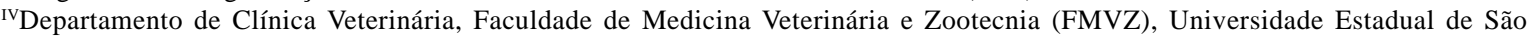
Paulo (Unesp), Botucatu, SP, Brasil.

`Departamento de Biologia Aplicada à Agropecuária, Faculdade de Ciências Agrárias e Veterinárias (FCAV), Univerisade Estadual Paulista (Unesp), Jaboticabal, SP, Brasil.

${ }^{\mathrm{VI}}$ Departamento de Clínica e Cirurgia Veterinária, FCAV, Unesp, Jaboticabal, SP, Brasil. 
como objetivo determinar se a imunorreatividade da p53 pela imunoistoquimica está relacionada a mutações no domínio central do TP53, em cães com linfoma.

Foram selecionados 12 cães com diagnóstico citológico de linfoma, com ou sem raça definida, entre machos e fêmeas, atendidos em um hospital veterinário, durante os anos de 2006 e 2007 . O estadiamento clínico do linfoma foi estabelecido para cada paciente. Os animais foram tratados com protocolo de quimioterapia constituído de sulfato de vincristina, L-asparaginase, ciclofosfamida, doxorrubicina e prednisona. Antes do tratamento, amostras de neoplasia foram obtidas mediante biópsia incisional. Empregouse a classificação histopatológica de Kiel (LENNERT \& FELLER, 1990), proposta para os linfomas não Hodgkin humanos. A determinação do imunofenótipo e a imunomarcação da p53 foram obtidas mediante técnica de imunoistoquímica, sendo utilizado anticorpo primário específico para cada reação.

Para determinação da imunorretividade da p53, utilizou-se o anticorpo primário policlonal antip53 (cód. NCL-p53-CM1, Novocastra), na diluição de 1:500, e o kit EnVision Dual-link (cód. K4063, DakoCytomation). As lâminas foram avaliadas por microscopia de luz. A avaliação da reatividade da p53 foi realizada pela contagem de todas as células presentes em cinco campos aleatórios em objetiva de 40x e as células positivas para o anticorpo. Esses valores foram transformados em percentual de células positivas. Considerou-se como reação positiva para a marcação da p53 apenas os linfomas que apresentaram o percentual mínimo de $5 \%$ de células positivas. As extrações dos DNAs genômicos das amostras de neoplasia foram realizadas utilizando-se o kit DNeasy Blood and Tissue (cód. 69506, Qiagen). Para as reações de PCR, foram confeccionados quatro pares de oligonucleotídeos iniciadores, a partir da sequência de nucleotídeos depositada no GenBank (www.ncbi.nlm.nih.gov) do National Center for Biotecnology Information (NCBI), acesso $n^{\circ} \mathrm{U} 62133$ (P1F 5'-CCCTACAGTCTTCGGAGCTG-3', P1R 5'AGACGCTCAACTGCTGAGCTG-3', P2F 5' CAGCTCAGCAGTTGAGCGTC-3', P2R 5'AAGGCACCACCACACTGTGTC-3', P3F 5'TGTGGTGGTGCCTTATGAGCC-3', P3R 5'GACTCCTAGCCACCСТCATC-3', P4F 5'ATGAGGGTGGCTAGGAGTCAG-3' P4R 5' AGCCTTGGTACCTGAAGGG-3’). Utilizou-se a enzima Platinum Taq DNA Polymerase high fidelity (cód. 11304-029, Invitrogen), considerada de alta eficiência na detecção de mutações pontuais. Os produtos obtidos foram purificados com o kit QIAquick PCR Purification (cód. 28104, Qiagen) e sequenciados em duplicata a partir do sistema de capilar MegaBACE 1000 (GE Healthcare). As sequências foram alinhadas com a sequência do cromossomo cinco do cão depositada no GenBank, (ref. NC_006587/Canis familiaris chromosome 5, whole genome shotgun sequence), com auxílio do programa Molecular Evolutionary Genetics Analysis (MEGA), versão 4.0.

A distribuição dos animais com relação à raça, ao sexo, à idade, à localização anatômica, ao estadiamento clínico, ao tempo de sobrevida, à classificação histopatológica (morfologia celular e grau de malignidade), ao imunofenótipo e à reatividade da p53 é apresentada na tabela 1.

A superexpressão da p53 por imunoistoquímica é usualmente atribuída à presença de mutações no gene que a codifica, aumentando a meia-vida da proteína entre oito e 12 horas (MARTINEZ-DELGADO et al., 1997). Apesar dos resultados obtidos pela imunoistoquímica, nenhuma mutação foi encontrada nas sequências analisadas. A forte positividade na maioria das células tumorais também pode estar associada com a estabilização da proteína por outro mecanismo diferente de mutação (HALL \& LANE, 1994). Dentro desse contexto, CESARMAN et al. (1993) analisaram a expressão da p53 em 15 amostras de linfomas anaplásicos humanos e observaram positividade em todos os casos. Apesar da alta frequência de positividade e de a porcentagem de marcação ser relativamente alta, apenas um caso apresentou mutação no gene TP53. Os autores afirmaram que o anticorpo monoclonal PAb 1801 utilizado no estudo também marca células com a p53 selvagem. Estudo semelhante foi realizado por OKA et al. (1998), que utilizaram o mesmo clone PAb 1801 para determinar a imunorretividade da p53 em linfomas humanos. A expressão da p53 por imunoistoquímica foi observada em 59/202 casos. Apenas 3/59 casos apresentaram mutações pontuais, detectadas pelo sequenciamento. Esses pesquisadores argumentaram que o acúmulo da p53 pode ser consequência da alta taxa de proliferação presente nas neoplasias malignas e reforçaram que a superexpressão da p53 mostrou-se intimamente associada com os linfomas de alto grau. VILLUENDAS et al. (1993) avaliaram 16 casos de linfomas humanos e concluíram que a expressão da p53 não está fundamentalmente envolvida com mutações no gene. Apenas 4/16 casos apresentaram mutações. Nesse mesmo estudo, a porcentagem de células marcadas variou de 1 a 52\%, sendo as maiores marcações (40, 50 e 52\%) observadas em linfomas de Burkitt. Curiosamente, na presente pesquisa, a maior marcação da p53 foi observada em um linfoma linfoblástico tipo Burkitt humano. Entretanto, vale 
Tabela 1 - Identificação, raça, sexo, idade, localização anatômica, estadiamento clínico, tempo de sobrevida, classificação histológica (morfologia celular e grau de malignidade), imunofenótipo e reatividade da p53.

\begin{tabular}{|c|c|c|c|c|c|c|c|c|c|c|}
\hline ID & Raça & Sexo & Idade (anos) & Loc. Anat. & Est. Clín. & $\begin{array}{c}\text { Tempo } \\
\text { sobrevida }\end{array}$ & Morf. Cel. & Grau malig. & $\operatorname{Imf}$ & P53 (\%) \\
\hline L1 & B. Terrier & $\mathrm{F}$ & 5 & $\mathrm{M}$ & IVa & 1 ano & CC-CB & BAIXO & B & 0 \\
\hline L2 & Buldog & $\mathrm{F}$ & 4 & M & IIIa & $>5$ meses & CC & BAIXO & B & 14,12 \\
\hline L3 & SRD & M & 10 & $\mathrm{C}$ & $\mathrm{Vb}$ & 7 dias & IB & ALTO & $\mathrm{T}$ & 19,13 \\
\hline L4 & Rottweiller & M & 6 & $\mathrm{C}$ & $\mathrm{Va}$ & 2 meses & $\mathrm{CB}$ & ALTO & B & 20,22 \\
\hline L5 & Poodle & $\mathrm{M}$ & 7 & M & $\mathrm{Vb}$ & 9 dias & $\mathrm{CB}$ & ALTO & B & 20,70 \\
\hline L6 & Rottweiller & $\mathrm{M}$ & 4 & M & $\mathrm{Vb}$ & 4 dias & AN & ALTO & $\mathrm{T}$ & 21,08 \\
\hline L7 & Boxer & $\mathrm{F}$ & 4 & M & IIIb & 30 dias & CB & ALTO & B & 24,12 \\
\hline L8 & Poodle & M & 7 & $\mathrm{C}$ & $\mathrm{Va}$ & 30 dias & AN & ALTO & $\mathrm{T}$ & 34,44 \\
\hline L9 & SRD & M & 9 & C & $\mathrm{Va}$ & 3 meses & $\mathrm{CB}$ & ALTO & B & 41,60 \\
\hline L10 & A. Pitbull & $\mathrm{F}$ & 5 & A & IVb & óbito & LB & ALTO & B & 50,56 \\
\hline L11 & SRD & M & 6 & $\mathrm{C}$ & $\mathrm{Vb}$ & óbito & LB & ALTO & $\mathrm{T}$ & - \\
\hline L12 & A. Pitbull & $\mathrm{F}$ & 3 & M & IIIa & 3 meses & IB & ALTO & B & - \\
\hline
\end{tabular}

ID: identificação do animal; LOC. ANAT.: localização anatômica; EST. CLÍN.: estadiamento clínico; MORF. CEL,: morfologia celular; GRAU MALIG.: grau de malignidade; IMF: imunofenótipo.

Para sexo, M: macho, F: fêmea; para localização anatômica, C: cutâneo, M: multicêntrico, A: alimentar; para morfologia celular, IB: imunoblástico, CC: centrocítico, CB: centroblástico, AN: anaplásico, LB: linfoblástico.

ressaltar que o clone utilizado no trabalho de VILLUENDAS et al. (1993) era o PAb 1801.

Para a maioria das neoplasias na espécie humana e canina, as mutações localizam-se na região compreendida entre os exons cinco e oito (CARON DE FROMENTEL \& SOUSSI, 1992; van LEEUWEN et al., 1997; CHU et al., 1998). As mutações previamente relatadas no gene TP53 de cães com linfoma, semelhantemente ao linfoma humano, encontram-se entre os exons cinco e oito (NASIR \& ARGYLE, 1999; VELDHOEN et al., 1998). As sequências obtidas nos cães com linfoma foram comparadas com a sequência do gene TP53 do genoma do cão, concluída em 2005 por LINDBLAD \& TOH e colaboradores. A ausência de mutação na região estudada associada à alta porcentagem de células positivas para p53 encontradas neste estudo podem ser decorrentes de mutações fora do domínio central do gene TP53, inclusive na região promotora. A inativação da p53 também pode ocorrer pela perda, sequestração ou ligação a outras proteínas, como proteínas virais (KLUMB, 2000). Ainda que a etiologia dos linfomas caninos não tenha sido elucidada, a relação entre os vírus e o desenvolvimento de linfomas na espécie humana é amplamente relatada e discutida na literatura há pelo menos 30 anos (JARRET, 2006). O vírus Epstein-Barr (EBV) tem ação oncogênica: LMPI atua na transformação de linfócitos; EBNA 5, na inativação do gene supressor de tumor TP53; e a proteína BHRF tem homologia com a proteína antiapoptoica BCL2. Esses achados reforçam a participação do vírus como um cofator na etiologia do linfoma de Burkitt. A p53 também pode apresentar-se ligada à proteína MDM2, sua antagonista, referenciada na maioria dos estudos que associaram a imunomarcação pela imunoistoquímica com a ausência de mutações (MARTINEZ DELGADO et al., 1997; OKA et al., 1998; KLUMB \& CAVALCANTI-JÚNIOR, 2002; ZACCHETTI et al., 2007). Em outra abordagem, MAESTRO et al. (1997) sugeriram que o acúmulo da p53 na ausência de mutação estaria associado à expressão da proteína p21, interferindo no ciclo celular. Por fim, outra hipótese a ser considerada é a regulação gênica por meio de mecanismos epigenéticos, como a metilação do DNA e a modificação das histonas (JONES \& BAYLIN, 2007). Esses mecanismos têm sido descritos em linhagens celulares de neoplasias linfoides na espécie humana (SAKAJIRI et al., 2005; OPAVSKY, et al., 2007) e é conveniente aceitar que ocorram de maneira semelhante em cães. Revisando os mecanismos epigenéticos de silenciamento gênico, BAYLIN \& OHM (2006) sugeriram que o aumento da expressão da SIRT1, uma enzima da família das histonas desacetilases, poderia aumentar o tempo de vida da célula por meio da modulação da p53. Contudo, os mecanismos epigenéticos de desenvolvimento do câncer ainda não foram completamente elucidados.

Diante do exposto e frente aos resultados obtidos, é possível concluir que a imunorreatividade da p53 pela imunoistoquímica não é indicativa de mutações no domínio central do gene TP53. Outros mecanismos diferentes de mutação no gene TP53 podem estar envolvidos na inativação da p53 em cães com linfoma. 


\section{COMITÊ DE ÉTICA}

Estudo realizado com aprovação da Comissão de Ética e Bem-estar Animal da FCAV, UNESP, Jaboticabal, SP (protocolo n.008255-07).

\section{REFERÊNCIAS}

BAYLIN, S.B.; OHM, J.E. Epigenetic gene silencing in cancer - a mechanism for early oncogenic pathway addiction? Nature Reviews Cancer, v.6, p.107-116, 2006. Disponível em: <http://www.nature.com/nrc/journal/v6/n2/execsumm/ nrc1799.html>. Acesso em: 21 abr. 2010. doi: 10.1038/ nrc1799.

CARON DE FROMENTEL, C.; SOUSSI, T. p53 tumor suppressor gene: a model for investigating human mutagenesis. Genes, Chromosomes and Cancer, v.4, p.1-15, 1992. Disponível em: <http://www3.interscience.wiley.com/journal/ 112703429/abstract>. Acesso em: 21 abr. 2010. doi: 10.1002/ gсc. 2870040102 .

CESARMAN, E. et al. High levels of p53 protein expression do not correlate with p53 gene mutations in anaplastic large cell lymphoma. American Journal of Pathology, v.143, p.845-856, 1993

CHU, L.L. et al. Genomic organization of the canine p53 gene and its mutational status in canine mammary neoplasia. Breast Cancer Research and Treatment, v.50, p.11-25, 1998. Disponível em: <http://www.springerlink.com/content/ v71780446540u181/>. Acesso em: 21 abr. 2010. doi: 10.1023/ A: 1006010526813 .

HALL, P.A.; LANE, D.P. p53 in tumour pathology: can we trust immunohistochemistry? Revisited! Journal of Pathology, v.172, p.1-4, 1994. Disponível em: <http:// www3.interscience.wiley.com/journal/110535034/abstract>. Acesso em: 21 abr. 2010. doi: 10.1002/path.1711720103.

JONES, P.A.; BAYLIN, S.B. The epigenomics of cancer. Cell, v.128, p.683-692, 2007. Disponível em: <http://www.cell.com/ abstract/S0092-8674(07)00127-4>. Acesso em: 21 abr. 2010. doi: 10.1016/j.cell.2007.01.029.

KLUMB, C.E. Epidemiologia do linfoma de Burkitt no Brasil. Revista Brasileira de Hematologia e Hemoterapia, v.22, supl.2, p.204-205, 2000.

KLUMB, C.E.; CAVALCANTI-JÚNIOR, G.B. Avaliação dos métodos de detecção das alterações do gene e proteína P53 nas neoplasias linfóides. Revista Brasileira de Hematologia e Hemoterapia, v.24, p.111-125, 2002. Disponível em: <http:/ /www.scielo.br/scielo.php?script=sci_abstract \&pid=S1516$84842002000200008 \& \operatorname{lng}=p t \& n r m=i$ so $\&$ tlng $=p t>$. Acesso em: 21 abr. 2010. doi: 10.1590/S1516-84842002000200008.

LENNERT, K.; FELLER, A.C. Histopathology of nonHodgkin's . 2.ed. Berlim: Springer-Verlag, 1990. 312p.

LINDBLAD-TOH, K. et al. Genome sequence, comparative analysis and haplotype structure of the domestic dog. Nature, v.438, p.803-819, 2005. Disponível em: <http:// www.nature.com/nature/journal/v438/n7069/abs/ nature04338.html>. Acesso em: 21 abr. 2010. doi: 10.1038/ nature 04338 .

MAESTRO, R. et al. Human non-Hodgkin's lymphomas overexpress a wild-type form of p53 which a functional transcriptional activator of cyclin-dependent kinase inhibitor p21. Blood, v.89, p.2523-2528, 1997.

MARTINEZ-DELGADO, B. et al. Correlation between mutations in p53 gene and protein expression in human lymphomas. American Journal of Hematology, v.55, p.18, 1997. Disponível em: <http://www3.interscience.wiley.com/ journal/50411/abstract>. Acesso em: 21 abr. 2010. doi: 10.1002/ (SICI)1096-8652(199705)55:1<1::AID-AJH1>3.0.CO;2-Y.

NASIR,L.; ARGYLE, D.J. Mutational analysis of the tumor suppressor gene p53 in lymphosarcoma in two bull mastiffs. Veterinary Record, v.145, p.23-24, 1999.

OKA,T. et al. p53 protein expression in non-Hodgkin's lymphomas is infrequently related to p53 gene mutations. Pathology International, v.48, p.15-21, 1998. Disponível em: <http://www3.interscience.wiley.com/journal/121422856/ abstract $>$. Acesso em: 21 abr. 2010. doi: 10.1111/j.14401827.1998.tb03822.x.

OPAVSKY, R. et al. CpG island methylation in a mouse model of lymphoma is driven by the genetic configuration of tumor cells. PLoS Genetics, v.3, p.1757-1769, 2007. Disponível em: <http://www.plosgenetics.org/article/ info:doi\%2F10.1371\%2Fjournal.pgen.0030167>. Acesso em: 21 abr. 2010. doi: 10.1371/journal.pgen.0030167.

SAKAJIRI, S. et al. Histone deacetylase inhibitors profoundly decrease proliferation of human lymphoid cancer cell lines. Experimental Hematology, v.33, p.53-61, 2005. Disponível em: <http:// www.sciencedirect.com/science?_ob=ArticleURL\&_udi=B6VP84F8S XDF-7\&_user $=10 \&$ \&_overDate $=01 \% 2$ F $01 \% 2$ F 2 005\&_rdoc $=1 \&$ _fmt=high\&_orig=search\&_sort=d\&_docancho $\mathrm{r}=\& \mathrm{view}=\mathrm{c} \&$ _searchStrId $=1304508560$ \&_rerunOrigin $=\mathrm{g}$ o o g l e \&_a c c t = C 000050221 \&_version $=1 \&$ \&_u rlVersion=0\&_userid=10\&md5=fca4274e138d82d563f83e8cda7bb2c3>. Acesso em: 21 abr. 2010. doi: 0.1016/j.exphem.2004.09.008

van LEEUWEN, I.S. et al. p53 gene mutations in osteosarcomas in the dog. Cancer Letters, v.1, p.173-178, 1997.

VELDHOEN, N. et al. Mutations of the p53 gene in canine lymphoma and evidence for germ line p53 mutations in the dog. Oncogene, v.16, p.249-255,1998.

VILLUENDAS R. et al. The expression of p53 protein in nonhodgkin's lymphomas is not always dependent on p53 gene mutations. Blood, v.82, p.3151-3156, 1993.

ZACCHETTI, A. et al. Immunohistochemical evaluation of p53 expression with different antibodies in malignant canine tumours with or without p53 gene mutation. Veterinary and Comparative Oncology, v.5, p.108-118, 2007. Disponível em: <http://www3.interscience.wiley.com/journal/117971024/ abstract>. Acesso em: 21 abr. 2010. doi: 10.1111/j.14765829.2006.00120.x. 